\title{
Documentar la obra de arte Reflexiones desde las bibliotecas de arte contemporáneo
}

\author{
Eduardo Camacho Rueda \\ Responsable del Departamento \\ de Documentación
}

Centro Andaluz de Arte Contemporáneo

\section{Resumen}

A partir de algunas de las notas características de la producción artística contemporánea, relacionadas con las técnicas y con la materialidad de la obra de arte, se reflexiona sobre los nuevos retos planteados acerca de la conservación y transmisión a futuras generaciones del arte actual y sobre el nuevo papel que les corresponde desempeñar a las Bibliotecas no sólo respecto a la conservación sino también respecto al tratamiento y difusión del arte contemporáneo, con especial referencia a la creación artística digital, haciendo hincapié en las bibliotecas como recurso pedagógico de primer orden.

\section{Palabras clave}

Bibliotecas de arte contemporáneo / Nuevos materiales artísticos / Conservación y protección / Nuevas tecnologías de la información / Enseñanza del arte

\section{Las Bibliotecas de arte ¿un tesoro escondido?}

En 1948, Paul Rivet escribía que "por importante que sea el papel que desempeña el museo en la educación popular, éste tiene otras muchas funciones que cumplir. Cada museo debe ser centro no sólo de iniciación popular, sino de documentación científica. Dependiente del museo tiene que haber una bien dotada biblioteca especializada..."I

La realidad, no obstante, es que más de medio siglo más tarde las palabras de Rivet no pasan de ser sólo un deseo. No hay más que leer las actas de los Congresos de los profesionales de la documentación que trabajan en bibliotecas de museos para darse cuenta de que la biblioteca sigue ocupando un lugar periférico y, a veces, sólo testimonial, dentro de los que son los centros de interés de la planificación y gestión de la mayoría de los museos y centros de arte. Basta con leer las monografías y Manuales que abordan los múltiples aspectos que se prejuzgan como esenciales para los museos para advertir que, sólo en contadas ocasiones, los autores dedican algún epígrafe, generalmente vago y vacío de contenido, y siempre como complemento dentro del capítulo dedicado a la Colección.

No es de extrañar que si tal es la consideración de la biblioteca dentro del propio museo, ésta siga siendo desconocida por el gran público. En 1994, una encuesta realizada con más de cuatro mil museos alemanes reveló que, aunque prácticamente todos los museos disponían de una biblioteca más o menos importante, el 90 por ciento de las personas interrogadas ignoraba su existencia ${ }^{2}$.

Las bibliotecas de arte se ven, de este modo, constreñidas al espacio físico del propio museo y, de hecho, en la mayoría de los casos, no están abiertas al público en general, limitándose, si acaso, a los investigadores y a los usuarios de la propia institución de la que dependen.

Desprovistas de personal especializado, con unos presupuestos escasos y unas instalaciones inadecuadas, las colecciones bibliográficas de los museos, en ocasiones de gran valor por la cantidad y, sobre todo, por la calidad de sus fondos, carecen de una mínima infraestructura para desarrollar las funciones $y$ los servicios que caracterizan a cualquier biblioteca.

\section{Las bibliotecas y las nuevas tecnologías}

Las bibliotecas de arte contemporáneo, como cualquier otra biblioteca, especializada o no, se ha visto so- 
Desprovistas de personal especializado, con unos presupuestos escasos y unas instalaciones inadecuadas, las colecciones bibliográficas de los museos, en ocasiones de gran valor por la cantidad y, sobre todo, por la calidad de sus fondos, carecen de una mínima infraestructura para desarrollar las funciones y los servicios que caracterizan a cualquier biblioteca.

metida en los últimos años a toda una serie de cambios impuestos por el impacto de las nuevas tecnologías en el tratamiento y difusión de la información. Nuevos equipos y herramientas para el procesamiento de la información; nuevas tecnologías para su difusión y nuevos soportes, se suceden en cadena a una velocidad exponencial que convierte en viejo lo que ayer era una novedad. En el mejor de los casos, el auténtico vértigo de los cambios sólo nos permite entrever los universos de posibilidades que se abren como abanicos ante nosotros. Con demasiada frecuencia, no obstante, quedamos deslumbrados por lo "sublime tecnológico", paradigma al fin y a la postre de lo que Manuel Castells denomina "sociedad informacional". La obsolescencia ha rebasado el ámbito de lo meramente tecnológico para ser asumida por el conjunto de la sociedad como parámetro con el que dimensionar el propio comportamiento social, desde la moda hasta las ideas, desde las actitudes hasta el arte.

La aplicación de las tecnologías a la transmisión y difusión de la información a través de las redes telemáticas, con Internet a la cabeza, ha venido a pulverizar las coordenadas espaciales y temporales por las que los hombres se han regido hasta hace apenas diez años. Tanto el espacio como el tiempo han sido transformados bajo el combinado paradigma de la tecnología de la información y de las formas y procesos sociales inducidos por el proceso actual de cambio histórico, afirma Castells ${ }^{3}$, y estas transformaciones tienen una incidencia decisiva, aún escasamente estudiada $y$, por lo tanto, asimilada por todos aquellos que, de una u otra forma, nos dedicamos al tratamiento de la información y a los procesos de difusión y comunicación que ello conlleva.

Se impone, pues, una reflexión en profundidad sobre el papel de los profesionales de la información, así como una redefinición, como veremos más adelante, de las funciones y servicios que deben desarrollar las bibliotecas, y, en concreto, las de arte contemporáneo, en estos momentos. Resulta descorazonador asistir a ciertos encuentros de profesionales de la información en los que lejos de profundizar sobre el nuevo escenario en que nos ha situado el desarrollo tecnológico, se tiene la sensación de estar participando en un mercado de productos informáticos de "última generación". De centros de investigación y difusoras de información, lo "sublime tecnológico" puede convertir a las bibliotecas y centros de documentación en consumidoras compulsivas de tecnología, que siempre ha de ser la última, para "estar al día" en esta carrera sin principio ni final.

Coincido con Isabel Ortega cuando señala 4 que "ante la enorme disponibilidad de información y su fácil acceso por los usuarios, los profesionales pueden tener una sensación de pérdida de su papel como intermediarios de la información. Sin embargo, los numerosos recursos en Internet representan un potencial informativo laberíntico para el usuario, y el profesional de la información tiene ahora la oportunidad de demostrar su capacidad en la selección de las fuentes que se adapten a las necesidades de cada momento". Es cierto que el hombre jamás ha tenido a su disposición tanta y tan diversa información; también lo es que nunca como hasta el presente ha sido tan complejo y ha estado, paradójicamente, tan alejado alcanzar conocimientos.

De hecho, uno de los problemas más graves con el que nos encontramos es el que nos ha tocado vivir en una época cargada de información. Este momento histórico se define por la acumulación de información, de datos, de imágenes, de ideas, de objetos; es la era de la superinformación, de la abundancia y al mismo tiempo de la escasez, de la ignorancia cada vez mayor sobre todo lo que nos afecta y concierne directamente. Sobre nuestra historia, sobre nuestro cuerpo, sobre nosotros mismos. Es también una época llena de frivolidad, donde, entre la abundancia de mensajes, se hace prácticamente imposible rescatar esa información que realmente nos interesa ${ }^{5}$.

\section{Las bibliotecas y el arte contemporáneo}

Si una biblioteca especializada, como es el caso que nos ocupa, se caracteriza por "aglutinar, tratar y di- 
fundir información relativa a un tema o a un grupo de temas afines" 6 , está claro que en una biblioteca dependiente de un Centro de Arte Contemporáneo, el tema o temas afines no pueden ser otros que los derivados de la producción artística de nuestros días. Y esta afirmación que más bien parece traída de la mano por Perogrullo, tiene unas consecuencias capitales, a nuestro juicio, sobre el papel, funciones y servicios de las bibliotecas de arte contemporáneo en nuestros días.

En toda biblioteca, la colección es el núcleo central y en la de arte ésta se nutre fundamentalmente de los catálogos de exposiciones. Mucho se ha escrito sobre la importancia del Catálogo como mediador, difusor y testigo de la obra artística. Desde los primeros catálogos, denominados "libros particulares" hasta las modernas ediciones en CD-ROM, los catálogos han sido compañeros insustituibles de cualquier acontecer artístico y, en ocasiones, ellos mismos, se han convertido en verdaderas obras de arte.

Hasta hace unos años, el catálogo de la obra de un artista significaba que ese artista había llegado a un momento en su carrera de una importancia tal que su obra merecía ser catalogada para así poder ser valorada, y considerada históricamente. Sin embargo, con el paso de los años, el sentido del Catálogo se ha ido modificando a la par que su proliferación, hasta el punto de que, como afirma Rosa Olivares, la historia del arte contemporáneo se ha asegurado su pervivencia a través del catálogo ${ }^{7}$, pudiéndose afirmar que, como lo entendemos hoy día, es hijo del boom del arte contemporáneo. Actualmente ningún artista por principiante que sea, por baja que sea su cotización, por poco interesante que sea su obra, se plantea realizar una exposición en la que no se edite un catálogo, porque lo que queda, después de todo, es la palabra escrita.

Los catálogos cumplen en sí mismos varias funciones: de una parte, testigos materiales y permanentes de un acontecimiento transitorio (una exposición), o del fondo artístico de un museo público o privado (una colección), o como evaluación crítica de la obra de un autor (catálogo razonado); de otra, vienen a certificar la existencia misma de la obra artística a través de su reproducción fotográfica o videográfica; finalmente, son per se, los mejores instrumentos de difusión y divulgación, a pesar de que, en la mayoría de las ocasiones, son editados por los propios organizadores de la exposición (museos, galerías de arte, etc.) y constan de tiradas muy reducidas por lo que podemos considerarlos como parte integrante de la llamada literatura gris, generalmente de difícil acceso.

Así pues, y de lo dicho hasta ahora, las bibliotecas especializadas en arte contemporáneo tienen un primer reto por lo que se refiere al proceso de selección de los fondos bibliográficos, debido a los miles de catálogos que se editan anualmente en el mundo. ¿Qué catálogos seleccionar para su adquisición e integración en el fondo de la biblioteca?.
La respuesta a este interrogante, común, por otra parte, al conjunto de centros de información en general, se ve, si cabe, complicada por otra de mayor calado y que se refiere a lo que se entiende por "arte contemporáneo".No es este el lugar ni el autor la persona adecuados para abordar esta cuestión, por otra parte muy controvertida. A la interrogante de ¿qué es el arte?, Achille Bonito Oliva responde que el arte es el conjunto de todas las obras publicadas en los libros de historia del arte ${ }^{8}$. Siguiendo a este autor podríamos decir que el arte de nuestros días es el que viene en los libros, catálogos, revistas y prensa de arte contemporáneo o todo aquel fenómeno de intencionalidad estética que pueda interesar al propio artista, comisario, crítico e historiador del arte, en definitiva a un público?.

Podría argumentarse que tal definición es tan vaga que, en realidad no limita nada. $Y$ esa es precisamente nuestra intención. Como profesionales de la documentación no parece que sea nuestro cometido valorar, cualificar o tipificar $y$, mucho menos censurar, la creación artística contemporánea. En todo caso, preferimos apelar al tiempo y dejar que él decida, con una perspectiva razonable, lo que los hombres y mujeres del mañana considerarán como arte, en la línea que señala Antonio Saura cuando escribe: "Antes de Marcel Duchamp no parece haber existido nada para muchos críticos y artistas, de la misma forma que sólo algunos privilegiados de nuestro siglo -el propio Duchamp, naturalmente, pero también Beuys, Warhol, Klein, Naumann, Christo, Ryman y Buren, por ejemplo- serán dignos de ser tenidos en cuenta como verdaderos héroes del arte sin arte. ¿Y si sucede exactamente lo contrario y tras el gran barrido de la historia que se avecina, fuesen precisamente ellos los primeros en ser olvidados, considerándoseles como los verdaderos pompiers de la modernidad, el amanerado y degenerado capricho de la sociedad, el fruto de un trágico malentendido? 10

Nuestro objetivo con estas reflexiones es más modesto y, a la vez, más necesario para el desarrollo cotidiano de las tareas propias de todo documentalista y bibliotecario enfrentado a una materia tan compleja, y a la vez, como vemos, tan etérea, como es el arte contemporáneo.

De éste nos interesa analizar precisamente aquellos aspectos que marcan una ruptura, en ocasiones radical, con el arte tal y como nos ha llegado en una tradición finisecular, marcado lógicamente, por avances, retrocesos y desarrollos más o menos importantes, pero con una línea de continuidad más que aparente.

Aunque podríamos, de seguro, analizar otros elementos, prestaremos atención a aquellos aspectos que más inciden sobre las funciones y servicios que debe prestar, a nuestro juicio, una biblioteca de arte contemporáneo: el tratamiento, la conservación y la difusión de la información, centrándonos en aquellas cuestiones que caracterizan a ciertas manifestaciones de la creación artística de nuestros días y que afectan directamente a uno o varios de los servicios y funciones señalados. 


\section{I. Desmaterialización del arte y nuevas tecnolo- gías aplicadas a la creación artística}

Bosco Gallardo, tras analizar la legislación española y andaluza sobre patrimonio histórico, concluye que la creación artística contemporánea queda fuera del ámbito jurídico establecido para la protección y tutela del patrimonio histórico, al no gozar de una edad que se estima como oportuna, aunque, como señala, desde la perspectiva de la definición de bien cultural absolutamente todo pasa a ser patrimonio en potencia. Tan sólo haría falta demostrar que el supuesto bien ofrezca algún tipo de relevancia. Ante el acusado desconocimiento del legislador sobre la creación artística contemporánea, este autor señala que "llegar a que el ciudadano y el técnico en ciencias del patrimonio otorgue a una manifestación artística del arte contemporáneo de ejemplar valía el título de patrimonio, sin el vestido de lo antiguo, de forma automática será la vía directa para que los mecanismos de la historia del arte y la administración cultural empiecen a generar sus fundamentos teóricos y sus instrumentos prácticos operativos "I.

Y este objetivo resulta apremiante por dos motivos: en primer lugar porque en el momento presente el propio concepto de "histórico" como medida de un tiempo pretérito ha sido literalmente aniquilado por unas perspectivas espacio-temporales que nada tienen que ver, como ya dijimos, con las que han "medido" el devenir de los " tiempos" hasta nuestros días. Existe una "conciencia social del tiempo" que convierte en histórico lo que apenas ha dejado de suceder; en segundo lugar, porque si algo caracteriza a la obra de arte contemporánea es su frágil materialidad, la caducidad de su soporte físico.

\subsection{La expresión estética y su reflejo en nuevas téc- nicas y materiales}

La búsqueda de nuevas formas de expresión estética ha llevado a los artistas contemporáneos a nuevos planteamientos en relación con los procesos técnicos de la creación artística y con los propios materiales.

A lo largo de la historia, los artistas se han preocupado mucho de la durabilidad y perdurabilidad de sus creaciones. De hecho, una parte destacada del aprendizaje de su oficio consistía en conocer bien las características y calidades de los materiales empleados en la producción de sus obras, conocimientos que se transmitían de generación en generación a través de los talleres artesanales, lo cual no eximía de la oportuna dosis de investigación y de innovación técnica y de las consecuencias imprevisibles que, en ocasiones, tales actividades exploratorias y experimentales deparaban, como es el caso, por ejemplo, de los fracasos técnicos de Leonardo da Vinci.

Tradición en las técnicas y sacralización de los materiales y de la propia obra de arte constituyen las notas dominantes de la producción artística hasta el siglo $X X$. Pero desde principios de esta centuria, la noción de perdurabilidad de la obra de arte es debatida y

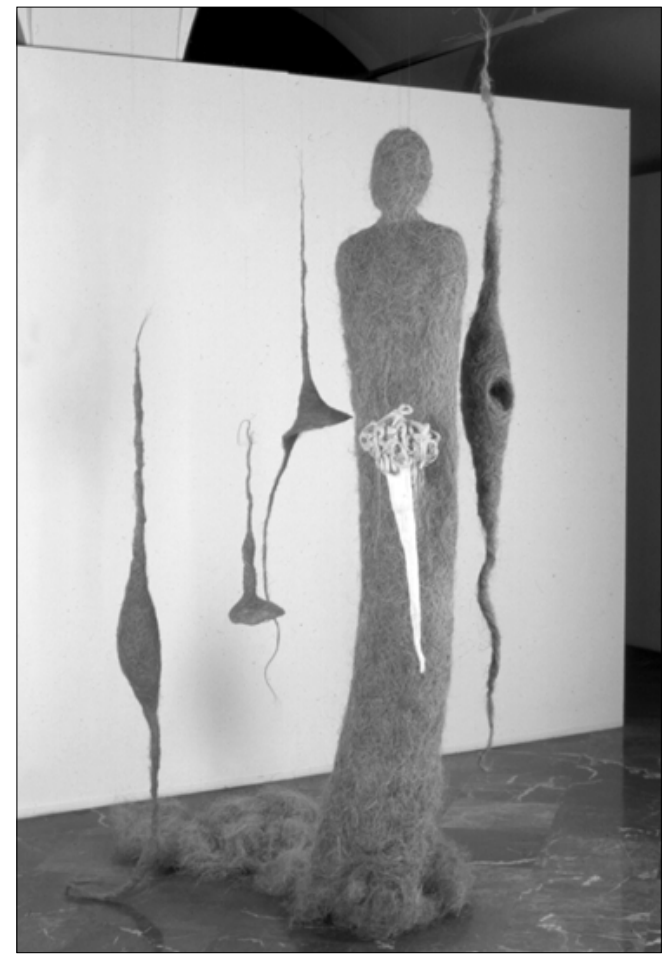

abiertamente cuestionada. Las reflexiones de André Breton sobre la obra efímera y los testimonios del propio Marcel Duchamp cuando afirma "creo que un cuadro, al cabo de un cierto número de años, muere como el hombre que lo ha pintado: después eso se llama historia del arte", son la expresión de un cambio radical de incalculables consecuencias tanto para la producción creativa actual como para el futuro.

"El arte contemporáneo descubre nuevas posibilidades en la observación de los medios técnicos como vía en sí misma de investigación plástica. Interesan los materiales y desde luego los materiales extraartísticos. Pero la materia no es ya considerada como algo inerte. Sujeta a transformaciones, altera sus componentes y cualidades, con consecuencias imprevisibles." I2. En ocasiones, es material destinado inevitablemente a la descomposición ${ }^{13}$.

El empleo como material de la obra de arte de restos de comida, excrementos, pelo natural, basuras, chatarras, valvas de moluscos o cáscaras de huevos, arenas y cartones, platos, vasijas rotos y un largo etcétera han hecho de la materia de la obra de arte un soporte físico con vocabulario y sintaxis propia. El siglo XX ha llegado a concederle los mayores honores y al mismo tiempo ha logrado neutralizarlo, reducirlo a algo impersonal y anodino, seriado y vulgar. De procedimiento inevitable y enojoso, ha pasado a contener buena parte del sentido de la obra 14 .

Este camino, iniciado con el cubismo, se ha mantenido inalterable a través de las vanguardias y ha caracterizado la historia del arte de todo el siglo XX. El minimalismo $y$, sobre todo el arte conceptual, marcan la culminación de esta radical transformación en la relación entre artista y materia, mostrando la obra de arte en el grado mínimo de materialidad, o incluso
I. Pepa Rubio. El jardín de la novia, Fibra vegetal, escayola y alfileres. $267 \times 195 \times 170 \mathrm{~cm}$ (Colección permanente del CAAC.) 
2. Nacho Criado. La herida alpina. Vidrio. Tomado del catálogo de la exposición "Piezas de agua y cristal". Museo Nacional. Centro de Arte Reina Sofía. Marzo-Mayo 1991.

3. Lucio Muñoz. La vaca. Oleo, metal, tela y áridos sobre madera. $230 \times 160 \mathrm{~cm}$. (Colección permanente del C.A.A.C.)
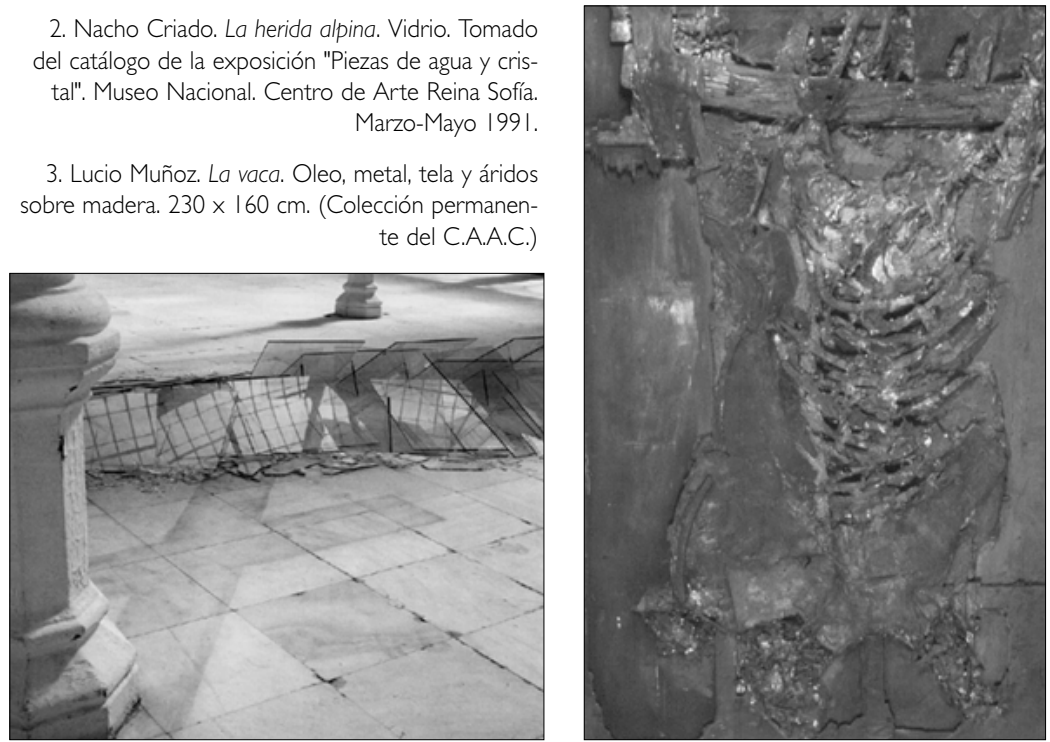

prescindiendo de ésta. Como señala Sol Lewit: la idea misma, incluso si no llega a hacerse visible, es tan obra de arte como cualquier producto terminado 15 .

Este esbozo muy simplificado sobre el empleo de nuevos materiales en la creación artística contemporánea viene a cuento en relación con el tema que nos interesa y que ha dado origen a emborronar estas páginas. Desde el ámbito de la documentación entendemos que el arte que se está produciendo en nuestros días es ya un bien cultural (no entramos en distinciones ni calificaciones estéticas) y será, o debería ser, parte del patrimonio histórico y cultural del mañana. Sucede, sin embargo, que, dadas las características matéricas de la obra artística contemporánea, ese mañana pude estar demasiado lejos o, simplemente, no llegar nunca.

Los agentes implicados en la creación artística de nuestros días mantienen actitudes muy diversas ante esta situación. Entre los artistas, los hay que han ido asumiendo las consecuencias lógicas de esta elección del material, es decir, su caducidad a corto plazo; otros ignoran la situación; por fin, los hay que luchan desesperadamente por mantener las técnicas ancestrales en una guerra anacrónica y de antemano perdida, ya que es cada vez más difícil conseguir materiales tradicionales y ya que en el mercado artístico contemporáneo, salvo excepciones, se supeditan estos aspectos a los contenidos plásticos y conceptuales de la creación; entre los museos y centros de arte, se extiende una sensación de resignación ante la fragilidad de las obras y la consiguiente inevitabilidad de su progresivo deterioro. En algunos casos, como el de la National Gallery de Canadá, se llega a exigir a los artistas, además de una completa información de las técnicas y los materiales empleados, piezas de repuesto para utilizar en caso de restauración; finalmente, entre los compradores y coleccionistas, se produce una cierta desconfianza a la hora de adquirir unas obras de arte, en algunos casos a precios muy elevados, sobre las que se tiene duda de su rentabilidad a medio y, sobre todo, largo plazo ${ }^{16}$.

\section{I.2. La Performance : expresión artística inmaterial}

En otro apartado de este artículo, se ha escrito que no es la misión del documentalista establecer criterios selectivos sobre lo que debe ser o no debe ser considerado arte contemporáneo, al margen de sus preferencias o sensibilidades artísticas personales.

Y esto viene a cuento cuando se trata de abordar la performance. Desde sus orígenes en el dadaísmo y el futurismo, esta forma de expresión artística ha atravesado por etapas de muy diverso signo en cuanto a su consideración por parte del público, de los críticos e incluso de los creadores contemporáneos. Denostada por muchos, desacreditada por otros, lo cierto es que está ahí como una forma de expresión artística y de entender el arte que no podemos obviar.

De límites y características imprecisos, podríamos destacar algunos elementos que forman parte del performance: el cuerpo como soporte del discurso, la duración en un tiempo limitado y acción, mostrados o expuestos en una presencia real y efímera 17

Desde el punto de vista que nos interesa, destacaríamos de la performance su inmaterialidad junto a su temporalidad y la imposibilidad de comunicabilidad más allá del público asistente al desarrollo de la acción.

De estas tres notas distintivas, se deriva necesariamente la intranscendencia innata de la performance como expresión artística, parametrizada temporalmente por un principio, un desarrollo y un final, sin continuidad física ni material. Así pues, excepto para el público asistente, la performance no existe ni se ha producido nunca e, incluso para los asistentes, sólo queda como experiencia vivida y, en todo caso, recreada en la memoria.

Documentar la performance se convierte así en una necesidad obvia, si lo que pretendemos es proyectar en el futuro esta forma de expresión.

La fotografía y el vídeo se convierten, de este modo, en los soportes materiales de la performance, hasta el punto de que "en el arte de acción, la documentación sobre el acontecimiento adquiere el estatuto de obra original" 18 .

A su vez, una vez "fijada" la performance a un soporte físico (fotográfico o videográfico), es posible su comunicabilidad a un público más amplio. Las performance de Ana Mendieta, Bruce Nauman, Sophie Calle, por poner un ejemplo, ilustran catálogos impresos y publicaciones en soporte vídeo para conocimiento de todos aquellos interesados en acercarse a estas formas de expresión artística. Si documentar una performance es contradictorio o no con el propio sentido de ésta es una cuestión que no nos toca dilucidar a los que nos dedicamos precisamente a documentarla $y$, por lo tanto, "conservarla" y transmitirla, actividades éstas que requieren, obviamente, de su plasmación física en cualquier tipo de soporte material. 
Y es concretamente ésta una actividad artística paradigmática del acto mismo de documentar el arte de cualquier biblioteca de arte contemporáneo. Los servicios de la biblioteca de cualquier museo y centro de documentación, en coordinación con otras áreas implicadas, deben asegurar la correcta y exhaustiva documentación de cualquier performance programada en la institución museística, se plasme o no, posteriormente, en un catálogo en papel o en cualquier otro soporte de difusión.

Hay que tener en cuenta que la performance ha ido adquiriendo carta de naturaleza entre las formas de expresión artística contemporánea, sobre todo a partir de los presupuestos teóricos enunciados por el arte conceptual de los años 60 y 70 "que hizo de la acción una demostración a ultranza de sus ideas, de su voluntad de no cosificación, de la insistencia en el proceso artístico interdisciplinar y no en el resultado, en los conceptos y no en los productos 19.

\subsubsection{Arte y nuevas tecnologías}

La aplicación al arte del ordenador y de las tecnologías digitales asociadas ha supuesto una serie de transformaciones radicales tanto en los modos de producción, distribución, exhibición, recepción y comercialización de los trabajos artísticos.

Como señala Gianni Romano, "el último capítulo de la intensa relación articulada en el siglo XX entre arte y tecnología está constituido por los numerosos encuentros entre Internet y el arte contemporáneo"20.

Pero esta relación arranca de la prehistoria de la informática, desde el origen mismo del ordenador. En efecto, hace cerca de cuarenta años que se suceden los ensayos de creación gráfica por vía informática. A comienzo de los setenta la mayor parte de las figuras generadas por ordenador se reducían a representaciones de formas geométricas en buenas perspectivas tridimensionales y con una coloración decorativa. A medida que se perfeccionaban los equipos y las técnicas se iban ampliando la gama de figuras representadas, incluyendo objetos más complejos.

José Antonio Millán se preguntaba ya en 1985 ¿qué podemos encontrar de específico, de nuevo, en los productos visuales con ordenador?. Y se respondía: la respuesta es limitada. Creaciones geométricas complejas, de gran belleza matemática e inaccesibles a otros medios; alguna exploración en el campo del color, que oscila entre el "fauvismo" y la psicodelia, y que es común al video-arte; generación sintética de formas abstractas, mundos imposibles... Hay, sin embargo, concluía, un aspecto exclusivo de estas tecnologías, imposible por otros medios, con el que tendrá forzosamente que contar un hipotético futuro arte con ordenador: las imágenes interactivas ${ }^{21}$.

Este hipotético futuro es desde hace unos años una tangible realidad, hasta el punto de que la interactividad, el Santo Grial para muchos, ha venido a modificar esencialmente la relación del espectador y la obra de arte, al dotar al espectador, mejor dicho al usuario, de la posibilidad de modificar la lectura de la obra a partir de sus interacciones, de realizar una selección, de producir cambios y, al mismo tiempo, de ser modificado por aquello que se recibe 22 .

Al mismo tiempo, el arte digital, interactivo e hipertextual ha venido a cuestionar varios de los conceptos finiseculares de la creación artística.

Hasta hace unos años, la idea de "original" era inherente a la obra de arte y junto a esta idea central, la concepción de la obra de arte como algo acabado, cerrado en sí mismo, concluido. Las obras producidas en los talleres de los artistas por los discípulos de éstos no alteraban esencialmente el concepto porque se entendía que eran ejecutadas bajo la dirección de éstos y según un boceto o plan artístico ideado por ellos.

Para muchos artistas actuales, sin embargo, la obra de arte en la era de la reproducción digital es física

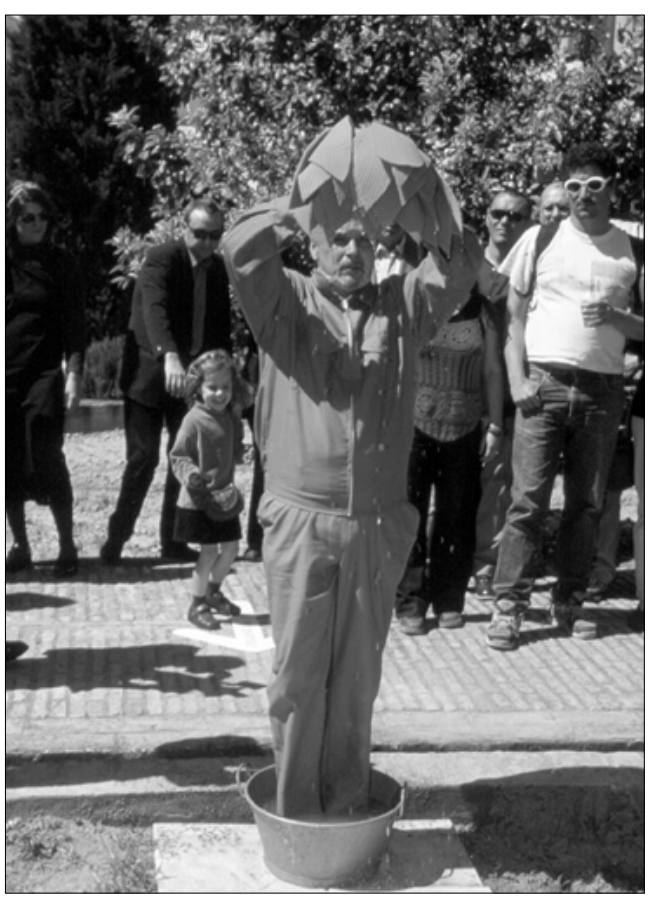

4. Miguel Benlloch Performance realizado por el artista durante la celebración en el CAAC de la exposición "Matitas divinas" Abril. 200।

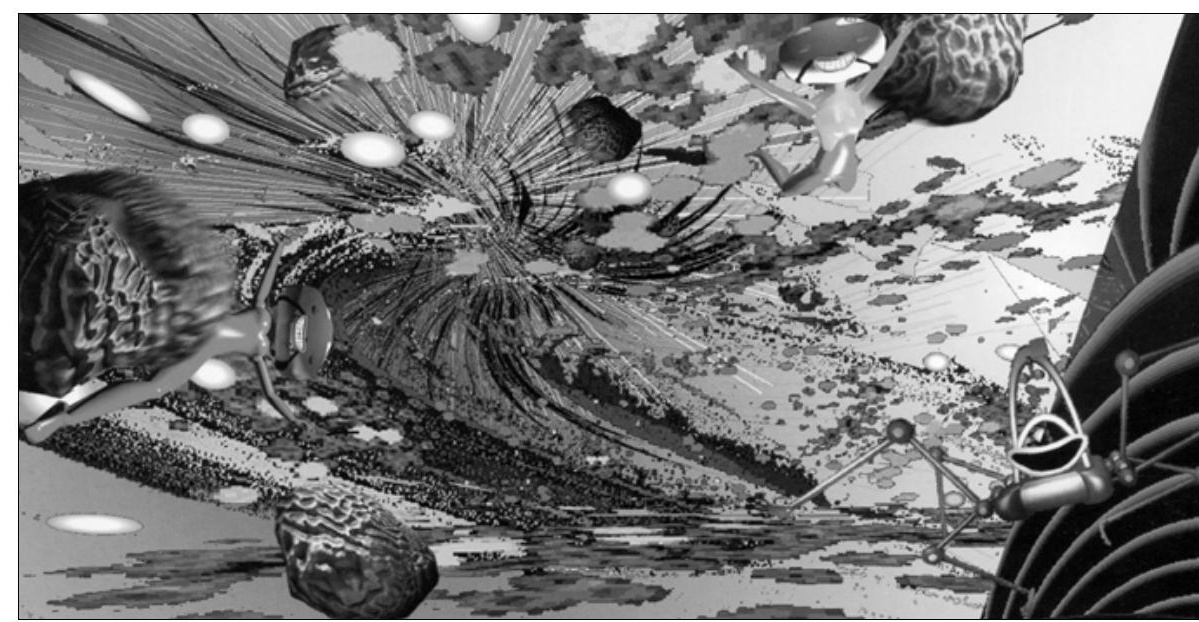


y formalmente como un camaleón. No existe distinción entre "original" y "reproducción" en medios fílmicos, electrónicos o de telecomunicaciones. Mientras que en el pasado, con los medios analógicos, cualquier copia implicaba una pérdida de resolución, con los medios digitales es posible una reproducción hasta el infinito sin degradación y con una absoluta perfección.

Las nuevas tecnologías permiten, además, recrear la obra que se convierte, de este modo, en una creación siempre inconclusa, empleando medios y herramientas informáticas cada vez más sofisticadas ${ }^{23}$.

En relación con este tema, el propio concepto tradicional de autoría queda cuestionado y sometido a una relectura desde una perspectiva radicalmente distinta y ello por varias razones. En algunos casos, la interactividad de la que hemos hablado lleva al artista a implicar al "espectador" de su obra digital en su propia producción, modificándola con sus propias aportaciones. Del autor individual se pasa, pues, a una autoría colectiva en la que participa el propio artista y la comunidad de espectadores que acceden a su obra; por otra parte, ante la sofisticación progresiva de los medios tecnológicos, el artista es consciente de que el concepto de autoría es cada vez más un proceso de colaboración con científicos, técnicos o ingenieros. Así, el concepto de taller del artista deja de tener sentido cuando la ciudad entera o el mundo virtual de la red, el Worl Wide Web, se convierten en su estudio y espacio de exposición.

Finalmente, el derecho de autor es otro de los aspectos más conflictivos y poco definidos cuando nos movemos en el ámbito de las nuevas tecnologías.

John Perry Barlow se pregunta que "si nuestra propiedad se puede reproducir infinitamente y distribuir de modo instantáneo por todo el planeta sin coste alguno, sin que lo sepamos, sin que ni siquiera abandone nuestra posesión ¿cómo podemos protegerla?, ¿cómo se nos va a pagar por el trabajo que hacemos con la mente?.

Este artista señala a mi entender el quid de la cuestión respecto a los problemas derivados de los derechos de autor y la propiedad intelectual en la red, al afirmar que la tecnología digital está separando la información del plano físico, que es donde la ley de propiedad de todo tipo siempre se ha definido con nitidez. A lo largo de la historia del copyright y las patentes, los pensadores han reivindicado la propiedad no de sus ideas sino de la expresión de las mismas, porque las primeras se consideran propiedad colectiva de la humanidad.

Pero Internet, agrega, puede llegar a constituirse con el paso del tiempo en el único medio de transmisión de información. Cuando esto ocurra, todos los bienes de la Era de la información existirán bien como pensamiento puro o como algo muy parecido al pensamiento : condiciones de voltaje que recorre la red a la velocidad de la luz y que de hecho se po- drán contemplar como píxeles brillantes o sonidos transmitidos, pero nunca tocar o decir que se "poseen" en el antiguo sentido de la palabra ${ }^{24}$.

De hecho, es una realidad cotidiana que si bien las leyes relativas a la reproducción no autorizada del software comercial son claras y severas, pocos las observan, porque es tan difícil hacer cumplir en la práctica las leyes sobre piratería del software y romperlas tiene ya tal grado de aceptación social, que sólo una minoría parece verse obligada, ya sea por temor o en conciencia, a obedecerlas,

Muchos artistas se declaran contrarios a la propiedad intelectual e incorporan a sus trabajos el icono de una $x$ encerrada en un círculo, sustituyendo la prohibición amenazadora del "Don't copy" por la invitación tentadora del "Do copy", como manifestación del deseo expreso de renegar de su autoría y de aceptar la naturaleza de unos medios que permiten que, en su lectura, la obra pueda seguir siendo construida o transformada.

Para las bibliotecas y centros de documentación de arte, este brevísimo esbozo de la producción artística y las nuevas tecnologías plantea un escenario novedoso y no exento de retos que será necesario afrontar y que, desde mi punto de vista, resitúa el papel y las funciones de las bibliotecas de arte como elementos no sólo de difusión y comunicación de la información sino también como copartícipes activos de la propia conservación de la creación artística de nuestros días.

\subsection{Algunas propuestas acerca del papel de las bi- bliotecas de arte}

Ya se ha mencionado la necesidad de redefinir el papel desempeñado hasta ahora por los profesionales de la información ante los nuevos escenarios abiertos por el impacto de las nuevas tecnologías. En el caso de los que nos dedicamos al tratamiento y difusión de la información sobre arte contemporáneo, este replanteamiento es, si cabe, más necesario y afecta también y, sobre todo, a los propios objetivos y servicios que deben prestar las bibliotecas a las que servimos.

Por lo que se refiere a la selección y adquisición de fondos bibliográficos, al margen de los procedentes de los catálogos de todo tipo, editados en papel y, cada vez con más profusión en soporte óptico, se debería prestar más atención a los documentos electrónicos disponibles en Internet y, en particular a las publicaciones electrónicas y periódicas como Aleph, Rhizome, Digital Desserts y otras, sobre todo aquellas que se van creando en el entorno geográfico en el que está ubicada la Biblioteca.

Es en este campo en el que los profesionales de la información debemos desarrollar esa labor de mediadores y comunicadores que nos demandan nuestros usuarios. Como en el resto de las áreas del co- 
nocimiento, Internet es, como la gran biblioteca que imaginara Borges, un gran laberinto en el que fácilmente se puede uno perder, pero donde también puede descubrir tesoros insospechados.

Y estos tesoros van más allá de las propias publicaciones electrónicas sobre arte contemporáneo. Sitios experimentales; otros a mitad de camino entre la experimentación y la información; sitios dedicados a la lectura y a la crítica; portales especializados, espacios, en fin, como el propio Rhizome (www.Rhizome.org), que cuenta en el actualidad con más de 6.000 miembros de 75 países, un ArtBase con 250 proyectos de net.art, un archivo con unos 1.600 artículos sobre arte y nuevas tecnologías, dos listas de correo, un e-zine y una librería 25 .

En este campo, como en muchos otros, debería fomentarse la colaboración y cooperación entre las bibliotecas de arte con el fin de elaborar guías y directorios actualizados de direcciones en Internet especializadas en arte contemporáneo y de calidad, con objeto de ponerlas a disposición de los usuarios de cualquier biblioteca especializada en esta materia.

Respecto a la creación artística en la red, las propias bibliotecas de arte deberían designar a un organismo responsable de un proyecto de conservación de las obras de arte creadas en y para la red. Debido a que Internet carece de espacios territoriales definidos, este organismo debería tener un ámbito de actuación internacional (la Sección de Bibliotecas de Arte de la IFLA, por ejemplo). Existe ya un proyecto, NEDLIB (Network European Deposit Library), llevado a cabo por las bibliotecas nacionales de Alemania, Finlandia, Francia, Italia, Noruega, Países Bajos, Portugal y Suiza, iniciado en enero de 1998, cuyo objetivo es precisamente crear una estructura básica sobre la que se pueda construir una red europea de bibliotecas depositarias de publicaciones electrónicas. En otros países ya se han empezado a desarrollar proyectos similares. Así en Suecia, la Biblioteca Nacional trabaja en un proyecto por el cual cada cuatro meses todas las páginas Web y gopher suecas así como los usenet groups y las listas de discusión públicas de este país son copiadas y almacenadas en cintas magnéticas. Del mismo modo, las publicaciones periódicas son integradas con la periodicidad que sea requerida. Hasta la fecha se controlan más de 39.000 sitios Web, con más de II millones de URLs en total. Experiencias como éstas, aplicadas al ámbito específico del arte contemporáneo, en sus múltiples vertientes, desde la creación hasta la información, podrían y deberían ponerse en marcha porque lo que está en juego es algo más que la disposición de información : la necesidad de dar un soporte físico, más o menos duradero, a la propia creación artística realizada en la red, como medio de tener la posibilidad de transmitirla a futuras generaciones que, de otro modo, se verían privadas de ella.

En relación con esta cuestión, hay que mencionar, no obstante, la obsolescencia y caducidad de los so-
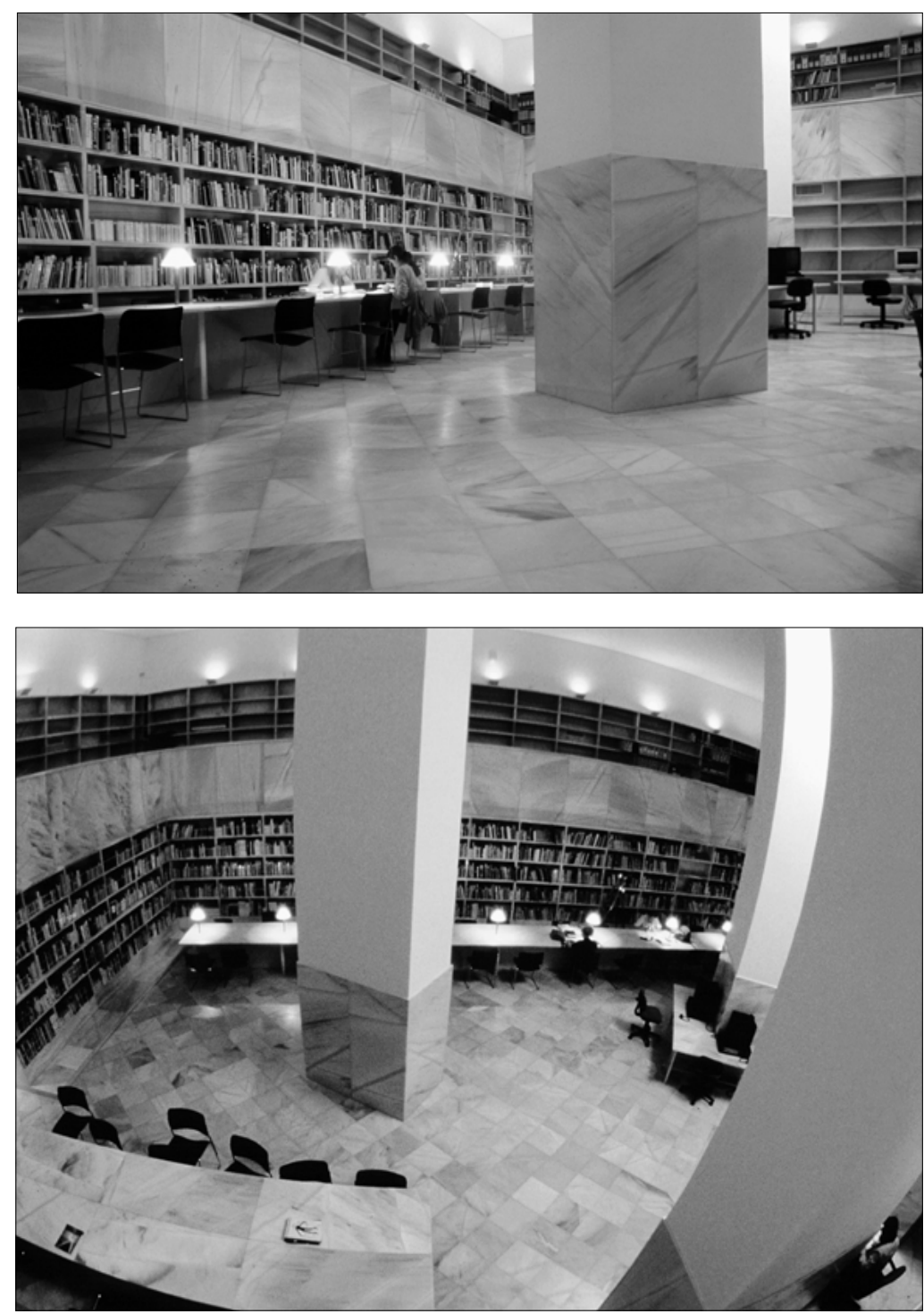

portes, formatos y equipos de almacenamiento ma6 y 7. Biblioteca del Centro Andaluz de Arte Contemporáneo. Sala de lectura. que este organismo se responsabilice de conservar los equipos y software necesarios para la lectura de los documentos en versiones antiguas o bien de convertirlos a los formatos superiores ${ }^{26}$.

En el ámbito más inmediato de la institución museística, el papel de las bibliotecas debe ser objeto de una profunda revisión, empezando por la propia consideración de las mismas como parte de un Sistema Integrado de Información.

Respecto a la propia colección permanente, las funciones de la biblioteca deben ir más allá de la mera recepción de elementos informativos con los que "documentar la colección". La actual estructura de la mayor parte de los museos y centros de arte, al menos de nuestro entorno más inmediato, consistente en encorsetar las funciones propias de cualquier museo en compartimentos estancos que desarrollan sus actividades de modo autónomo e independiente es un lastre insoportable para el funcionamiento global de la institución, impidiendo el necesario flujo infor- 
mativo, el tratamiento coordinado de la información recibida y generada por la actividad diaria del museo e impidiendo, o dificultando, el acceso de los usuarios a unos bienes culturales que forman parte de su patrimonio y acervo cultural.

Una de las facetas que deberían ser asumidas por las bibliotecas de arte es la de documentar la actividad artística de la institución a la que pertenecen.

A pesar de la importancia del Catálogo como testigo y "fedatario" intemporal de la creación artística de nuestros días, no todos los actos programados por las instituciones museísticas tienen su correspondiente reflejo en la edición de un catálogo y no todos los catálogos son fieles reflejos del acontecimiento artístico que vehiculan.

En coordinación con las áreas correspondientes (Colección, Actividades, Gabinete de Prensa, etc.), los servicios bibliotecarios deberían garantizar que las actividades desarrolladas son conveniente y adecuadamente documentadas. Talleres en los que artistas y alumnos crean objetos artísticos en los que se pierde toda la actividad procesual; performance que pasan inadvertidos sin quedar ninguna huella de su efímero desarrollo; instalaciones y esculturas cuya percepción visual y significación simbólica son modificadas significativamente por su inserción en espacios determinados; e incluso conferencias, entrevistas y ruedas de prensa donde los artistas reflexionan sobre su obra, son algunos de los aspectos que deben ser documentados, de los que debe quedar una memoria física, fijada al soporte que se estime más adecuado según el tipo de acto.

En este sentido no deja de ser encomiable la labor desarrollada por el Servicio de Documentación del Museo Nacional Reina Sofía, a través de su Departamento de Medios Audiovisuales, cuyo resultado son los cerca de 150 vídeos de las exposiciones celebradas en el Museo desde su creación en el año 1986.

Para el desarrollo de ésta y otras funciones, las bibliotecas requieren del apoyo decidido del staff de la institución a la que pertenecen, expresado tanto en medios personales como materiales, así como en la propia concepción del Museo como un Sistema de Información cuyo objetivo es el tratamiento y difusión de información a un público que, aprovechando las nuevas tecnologías de la información, podría ser potencialmente más numeroso. Odile Tarrête señala que "desde 1996, toda la colección del Fine Art Museum de San Francisco está disponible en línea a través de Internet: fotos y reseñas de todas las obras, incluso las que están en reserva o embaladas, lo que dará la mayor difusión posible a todo su fondo, la posibilidad de que los editores elijan los documentos poco conocidos y que el gran público acceda a algunas obras nunca expuestas por su gran fragilidad." Según Tarrête es la biblioteca la que debería encargarse de este trabajo de difusión y además lo necesita para asegurar plenamente su transforma- ción en un verdadero centro de recursos documentales, capaz de reunir toda la información disponible en el museo y redistribuirla en función de la demanda y bajo distintas formas en la biblioteca y entre el público ${ }^{27}$.

Por último, no quisiera dejar de mencionar, aunque brevemente, otra de las funciones que deberían desarrollar las bibliotecas de arte que se me antoja de suma importancia: la de apoyo a la actividad pedagógica desarrollada por los centros de arte contemporáneo.

En relación con el arte actual hay quien se pregunta ¿qué raro patrimonio es éste que, a pesar de poseerlo, deben enseñarnos a identificarnos con él? ${ }^{28}$.

Y lo cierto es que, si como afirma Rosa Olivares "el arte actual no es tan diferente ni tan radical, sino que obedece a las mismas líneas de tensión vital que siempre han apretado al hombre" y la diferencia sólo está, según ella, en el tiempo en que vivimos, algo sucede porque los hombres y mujeres de la calle no parecen apreciar la creación artística de nuestros días como algo próximo, como una expresión plástica de la realidad que les ha tocado vivir.

Rosa Olivares agrega "un vídeo, una escultura, una fotografía, una pintura, una instalación, son simplemente mensajes en botellas lanzados al mar que buscan que alguien los recoja y los lea" 29 . Pero es un hecho constatable estadística y sociológicamente que el arte contemporáneo no "atrae". Se trata, a mi entender, de un problema de aprendizaje, de una cuestión de decodificación de las claves de un mensaje que se muestra, en demasiados casos, como críptico. Se trata, al fin y a la postre, de "enseñar a mirar".

Isabel Duran, al abordar esta problemática, apuesta clara y apasionadamente por utilizar el arte contemporáneo como una de las mejores herramientas de aprendizaje del mundo en que vivimos. $Y$ se pregunta qué es lo que está pasando porque el público entra en los museos de arte contemporáneo y sale aturdido, aburrido y, lo que es peor, confundido: ies esto arte?, ¿qué ha pasado con la belleza?. Y agrega "nunca en la historia del arte se han observado posturas más reaccionarias contra el arte de su tiempo" 30 .

Para Isabel Duran, se impone con urgencia un replanteamiento de la enseñanza del arte por parte de los responsables en todas las esferas implicadas, de alguna u otra manera, en el proceso educativo. Desde las escuelas, las universidades y, por supuesto, desde los propios museos y centros de arte. El objetivo es el de "enseñar a mirar", con la finalidad de superar la absurda dicotomía entre el espectador y el objeto artístico.

Y en este replanteamiento de los presupuestos y de las realidades sobre los que se ha basado hasta ahora la función pedagógica del museo, la biblioteca debe jugar un papel que hasta ahora, en la mayoría de 
los casos, se le ha negado o, simplemente y por diversos factores, no ha asumido, porque contribuir con sus recursos informativos y documentales a facilitar el aprendizaje del arte actual revertirá en un futuro en que esos mismos recursos sean más y mejor valorados y accesibles al conjunto de los ciudadanos.

Tales son algunas de las reflexiones que suscita el arte contemporáneo en alguien cuyo trabajo consiste precisamente en darlo a conocer. Reflexiones y muchas preguntas sin respuesta, dudas sobre lo que ha sido y, sobre todo, sobre lo que será la creación artística en los próximos años; interrogantes sobre lo que quedará en el camino y sobre lo que seremos capaces de "salvar" para el futuro; reservas sobre nuestra capacidad para hacer que el ciudadano medio disponga de los elementos críticos y discursivos que le permitan juzgar, rechazar o gozar de la obra de un artista. Y, finalmente, temores ante el imparable poder tecnológico, desde la conciencia de que "a medida que aumenta el abismo abierto entre el luminoso mundo de la realidad virtual y los hechos palpables de la desigualdad económica y la depredación del medio ambiente" 31 , lo "sublime tecnológico" no deja de ser como una máquina de Jano, una máquina de liberación y un instrumento de represión.

\section{Notas}

I. Cita tomada de TARRETE, Odile. Un tesoro escondido : las bibliotecas y los centros de documentación de los museos. Museum International, 1997, n 195, p. 43

2. TARRETE, Odile. Op. Cit. p. 44

3. CASTELLS, Manuel. El espacio de los flujos, en La era de la información. Economía, sociedad y cultura. Vol. I. La Sociedad red. Madrid : Alianza editorial,, 1996, p. 410

4. ORTEGA VAQUERO, Isabel. Webs de documentación e información : aproximación y valoración a los recursos de ámbito nacional. Boletín del Instituto Andaluz de Patrimonio Histórico, 1999, n²6, p. 175

5. OLIVARES, Rosa. Ultimas tendencias. Revista Lápiz, 1992, nº 84, p. 37

6. VELLOSILLO GONZÁLEZ, Inmaculada . Las bibliotecas especializadas, en Manual de Biblioteconomía. Madrid : Editorial Síntesis . 1996, p. 380. (Serie Biblioteconomía y Documentación)

7. De la importancia del catálogo en la historia del arte, es buena prueba las exposiciones que han tenido como eje central el Catálogo en sí, así como las publicaciones que han reflexionado sobre su papel, función y desarrollo histórico. Entre estas últimas mencionaremos el monográfico dedicado por el Centre Georges Pompidou en el número doble 56/57 de Les Cahiers du Musee National d'Art Moderne (1996), titulado precisamente "Du Catalogue".

8. BONITO OLIVA, Achille. ASI. El estado del arte (y también de la crítica). Revista LÁPIZ. 1988, nº 61, p. 22

9. GALLARDO, Bosco. Problemas y perspectivas en torno a la tutela del patrimonio artístico del siglo XX. Boletín del Instituto Andaluz de Patrimonio Histórico. $n^{\circ} 29$, p. 48

10. SAURA, Antonio. La muerte del arte. Arte y Parte. Revista trimestral de información artística. 1997, nº 6, p.5 |

I I. GALLARDO, Bosco. Ibidem, p. 5 |

12. BERNÁRDEZ SANCHÍS, Carmen. El material interrogado. Revista LAPIZ, I994, n 105, p.36-37

13. Cuando Nacho Criado presentó en el Palacio de Cristal, en 1991, su obra Umbra zenobia dejó que microorganismos vivos proliferaran sobre paneles de cristal produciendo manchas y formas que activamente modificaban la apariencia de la obra.
14. BERNÁRDEZ SANCHÍS, Carmen. La estatua hambrienta. Revista LAPIZ, 1996, $\mathrm{n}^{\circ}$ ||4, p. 42

15. Citado por BERNÁRDEZ SANCHÍS, Carmen. El material interrogado. Revista LAPIZ, 1994, n I05, p.44

16. RUIZ DE ARCAUTE, Emilio. Conservar el arte contemporáneo, un reto de hoy. Revista LAPIZ, 1987, n 44, p.38

17. TORRES, David G. La vigencia oculta de la performance. Revista LAPIZ, 1999, n I32, p. 22

18. GALLARDO, Bosco. Ibidem, p.54

19. HAC MOR, Carles y XARGAY, Esther. El dedo en la llaga. Revista LAPIZ, 1995, n I07, p. 69-70

20. ROMANO, Gianni. Estrategias del arte en la red. Revista LAPIZ, 2000, n 168 , p. 49

21. MILLÁN, José Antonio. El pincel de bits. ¿Hacia un arte por ordenador?. Revista LAPIZ, 1985, n²7, p. 35

22. BADIA, Montse. Prácticas artísticas y nuevas tecnologías : nuevas tipologías. Revista LAPIZ, 2000, n I56, p. 54

23. BADIA, Montse. Ibidem, p.53

24. BARLOW, John Perry. EL PASEANTE. Vender vino sin botellas. La economía de la mente en la red global, $n^{\circ}$ 27-28, p. II

(25) Artículo aparecido en el suplemento Ciberp@is del día 12 de abril de 200I, p. II, titulado La organización Rhizome fomenta el diálogo crítico sobre el net.art

26. PONS, Amadeu. Educación y Biblioteca, 1999, n 100, p. 58

27. TARRETE, Odile. Ibidem, p. 48

28. Palabras de Antonio Limón, citadas por Bosco Gallardo en el artículo ya reseñado anteriormente.

39. OLIVARES, Rosa. Ultimas tendencias. Revista LAPIZ, I993, nº 84, p.44

30. DURÁN, Isabel. Una asignatura pendiente. El arte contemporáneo. Revista de Museología, 1996, nº 8, p.31

31. DERY, Mark. Velocidad de escape. La cibercultura en el final del sig/o. Traducción de Ramón Montoya Vozmediano. Madrid: Ediciones Siruela, 1998. 